\title{
RELAÇÕES DE TRABALHO E REESTRUTURAÇÃO PRODUTIVA NO CAPITALISMO OCIDENTAL: AS CRISES E OS (NOVOS) DISPOSITIVOS DE CONTROLE
}

\author{
$\longrightarrow$ \\ Jandir Pauli *
}

\begin{abstract}
Resumo
Este artigo analisa as crises e as consequentes reestruturações produtivas que marcaram a história do capitalismo ocidental sob a perspectiva dos novos dispositivos que marcaram as relações de trabalho em cada uma dessas etapas. Para isto, desenvolve uma breve história do trabalho a partir dos novos dispositivos de controle sobre os trabalhadores instalados no percurso das reestruturações. O plano de fundo é apresentar elementos teóricos para justificar que, além do discurso da humanização do trabalho, entraram em jogo novos elementos de captura da subjetividade operária para ampliar a acumulação de capital. Estes pressupostos levam a concluir que, na atualidade, o desafio da superação da precariedade do trabalho ainda persiste e torna-se um imperativo social diante da importância do trabalho como elemento-chave da socialização humana.
\end{abstract}

Palavras-chave: Relações de trabalho. Precarização. Reestruturação produtiva.

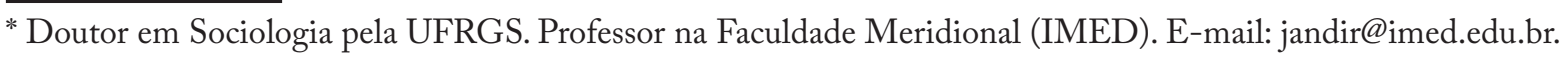




\section{Introdução}

Este estudo tem a pretensão de traçar uma linha da mudança na percepção do trabalho e da alteração dos mecanismos de apreensão da subjetividade operária na modernidade. $\mathrm{O}$ objetivo dessa localização é identificar os principais debates que indicam o atual estágio do capitalismo e problematizar as principais perspectivas do mundo do trabalho. O plano de fundo desta análise aponta para a ideia de que todas essas alterações não perceberam o trabalho como categoria emancipadora do ser humano, mas reforçam a ideia de que em todas as mudanças do mundo do trabalho os mecanismos de controle e de subordinação dos trabalhadores incidiram na precarização do trabalho, percebido sempre como um simples custo no processo produtivo.

O ponto de partida desta análise será a crítica à economia política clássica pela descaracterização do trabalho, mostrando que esta forneceu conteúdo ideológico para a sua precarização à medida que "liberou" a instalação de diversos mecanismos de captura e coação da subjetividade operária. Estes mecanismos se manifestaram através do controle sobre o tempo dos trabalhadores no surgimento do putting-ou-system e na passagem ao sistema fabril das work-houses. Nesta perspectiva, veremos que a introdução da maquinaria e a Organização Científica do Trabalho (OCT), que estão na base da introdução dos modos de produção taylorista e fordista que orientaram o capitalismo entre o final do século XIX e a primeira metade do século XX, assim como o toyotismo, a partir dos anos 50, representam uma nova estratégia de organização da produção para subordinar os trabalhadores e capturar sua subjetividade. Na segunda parte, serão discutidas algumas perspectivas contemporâneas da reestruturação produtiva que leva em consideração a influência neoliberal na organização do mundo do trabalho. Aparece com destaque a dimensão abstrata do trabalho, mesmo quanto se trata do consentimento operário.

O itinerário geral dos tópicos procura demonstrar que as reestruturações produtivas que se sucedem na história do modo de produção capitalista, e que são provenientes de crises cíclicas, embora divulguem a humanização do trabalho, não o ressignificam na sua dimensão subjetiva e emancipadora. 


\section{A crítica à Economia Política liberal}

Antes de adentrar na significação da categoria "trabalho", é necessário observar uma variável que incide diretamente na sua conceituação, isto é, a mutação do próprio conceito no desenrolar da história ocidental. Arendt (1983, p. 94) afirma que,

[...] ao contrário do que ocorreu nos tempos modernos, a instituição da escravidão na Antigüidade não foi uma forma de obter mão-de-obra barata nem instrumento de exploração para fins de lucro, mas sim a tentativa de excluir o labor das condições da vida humana. Tudo o que os homens tinham em comum com as outras formas de vida animal era considerado inumano.

Esta afirmação ilustra a rejeição dos gregos para com o trabalho por compreendê-lo como restritivo à liberdade humana, já que estava ligado ao mundo da necessidade, o que, por sua vez, expressaria a contradição entre o animal laborans e o animal rationale.

Do ponto de vista etimológico - e isto implica um nível de conceitualização - a palavra "trabalho" deriva do verbo latino Tripalium, e significa "tortura”. Na idade média, Tripalium era um instrumento com extremidades pontiagudas no qual os agricultores batiam as espigas para debulhá-las. Evidências indicam que este instrumento teria sido utilizado nas práticas de tortura e suplícios públicos.

No entanto, o mundo moderno ressignifica o trabalho transformando o seu caráter de negativo como atividade humana indigna para a condição de artífice da libertação e emancipação do ser humano. Esta ressignificação foi ancorada em dois pilares fundamentais: a Reforma Protestante, que instituiu uma ética religiosa do trabalbo a partir da compreensão do trabalho como indice de predestinação e salvação humana, e a Economia Política, que ainda nos séculos XVII e XVIII procurou dar base a este novo modus vivendi do homem moderno, fundamentando o trabalho como produtor de riqueza e desenvolvimento social.

Para os representantes da economia política clássica, como Adam Smith (1723-1790) e David Ricardo (17721823), o valor de uma mercadoria se identifica necessariamente com o trabalho dispendido na sua produção. Posteriormente, Karl Marx (1818-1830) ampliou o escopo dessa reflexão ao incorporar ao trabalho uma dimensão social. Quando denuncia, 
ainda nos Manuscritos Econômico-Filosóficos de 1844, que "a economia política considera o trabalho abstratamente como uma mercadoria" e que "não é apenas força produtiva ou um dado na conta dos custos de produção, mas essencialmente atividade humana" (MARX, 1989, p. 115), o autor parte da premissa de que o trabalho deve ser compreendido "enquanto processo de gênese humana” (MARX, 1989, p. 251) e de humanização através da relação com a natureza. Segundo o autor, os economistas clássicos auferiram à economia um conteúdo ideológico para a coação dos trabalhadores e em "defesa da fábrica", procurando convencer "os setores amedrontados da sociedade de que os trabalhadores ingleses lutavam contra a irreversibilidade de uma lei da própria história, o que esvaziou o conteúdo político das contestações dos trabalhadores" (DECCA, 1984, p. 52-54). Em outras palavras, quando a economia política afirmou o trabalho como produtor de riqueza, implementou um processo de coação para este modelo, procurando captar a subjetividade do trabalhador moderno. Neste sentido, é importante observar como esta variável se comportou nos processos de reestruturação do capitalismo, conforme veremos a seguir.

\section{A maquinaria e o surgimento da fábrica}

O capitalismo moderno se estrutura a partir da coação dos trabalhadores a se envolverem em um novo paradigma produtivo. Esta é uma característica marcante da passagem do modelo feudal para o putting-out-system ou produção por demanda, em que surge o papel imprescindível do capitalista como um "organizador da produção” (MARGLIN, 1980, p. 48), através do controle da distribuição e do mercado da produção artesanal. Embora neste sistema os trabalhadores ainda possuam o domínio tecnológico sobre a produção, o putting-out-system institui uma hierarquia social porque obrigou os trabalhadores a dependerem deste intermediário para terem acesso ao mercado e à matéria-prima.

$\mathrm{O}$ surgimento da fábrica abre a possibilidade de reunir os trabalhadores "sob um mesmo teto" não necessariamente ou prioritariamente para otimizar a produção de mercadorias, mas para controlar o processo de produção, abrindo a possibilidade de expropriação do saber dos trabalhadores.

No entanto, o capitalismo fabril manufatureiro irá precisar de uma subjetividade disciplinada, o que vai acontecer a partir da 
ressignificação do tempo para o disciplinamento do trabalhador através de componentes externos - como a introdução do relógio como marcador do tempo -, e por aspectos de "internalização da disciplina" promovidos pela escola e pela religião, através da ética puritana de retórica moral. Neste ponto, a obra de Max Weber A Ética Protestante e o Espírito do Capitalismo é uma referência na ilustração de como a ética protestante considerou o trabalho como meio para alcançar a graça e ratificar a predestinação. O historiador Thompson (1998) cita alguns fatores que vão contribuir na internalização do tempo: a divisão e a supervisão do trabalho, o uso de sinos e relógios nas cidades e fábricas, a criação de incentivos em dinheiro, o uso da pregação religiosa e do ensino escolar (THOMPSON, 1998, p. 297). O autor afirma que o tempo era pouco sincronizado no putting-out-system, pois era baseado na tarefa (quantidade a ser produzida).

Segundo o mesmo autor, nas sociedades pré-industriais, as formas de percepção do tempo se constituíram a partir da concepção de trabalho na sua relação com os ritmos naturais. É o caso, por exemplo, dos portos ingleses, onde o trabalho era padronizado pelo ritmo das marés, o que garante que neste caso são os próprios trabalhadores quem vão deter o controle de sua vida produtiva. É interessante a explicação de Thompson sobre a "Santa Segunda-Feira", considerada um descanso prolongado, mas que se tornou alvo de folhetos vitorianos sobre a temperança que associavam este descanso com bebedeiras no fim de semana. Além disto, foram instituídos baixos salários para prevenir o ócio e controladores de tempo, delatores e multas e "os piores capitalistas tentaram expropriar os trabalhadores do conhecimento sobre o tempo" (THOMPSON, 1998, p. 294).

O sistema fabril introduz a necessidade de uma sincronização do trabalho e de um melhor aproveitamento do tempo do trabalhador. Assim, o tempo para marcar trabalho por tarefas foi sendo substituído pelo tempo de trabalho através da contratação de mão de obra por horário marcado, caracterizando o tempo como mercadoria; ou, na afirmação de Thompson: "o tempo agora é moeda: ninguém passa o tempo, e sim o gasta" (THOMPSON, 1998, p. 272). Desta forma, o relógio passa a fazer parte da vida das pessoas no século XIV e isto afetará substancialmente a disciplina no trabalho, conjugado a fatores $\mathrm{da}$ retórica moral de que o tempo não poderá mais ser recuperado e que o juízo final julgará os que não aproveitam o tempo de 
maneira virtuosa, administrando-o contra o desperdício; "sem esta disciplina do tempo, não teríamos as energias persistentes do homem industrial; pois, adotando as formas do metodismo, do stalinismo ou do nacionalismo, essa disciplina chegará ao mundo em desenvolvimento" (THOMPSON, 1998, p. 300). Esta definição corrobora a perspectiva de Decca $(1984$, p. 49) de que "onde quer que a fábrica tenha se tornado vitoriosa historicamente, o tema da industrialização se consolidou como um dos universos da dominação cultural [...] e de dominação e coerção sobre o trabalhador dentro e fora da fábrica".

\section{Organização Científica do Trabalho e o Toyotismo}

\section{Karl Marx, em O Capital, argumenta que, \\ [...] a manufatura não podia abarcar a produção social em toda a sua extensão, nem revolucioná-la em suas entranhas. Sua obra de artifício econômico se viu coroada pela vasta rede do artesanato urbano e da indústria rural. Ao alcançar certo grau de desenvolvi- mento, sua base técnica, estreita, tornou-se incompatível com as necessidades da produção que ela mesma havia criado. (MARX, 1989 apud NETO, 1989, p. 24).}

O autor está querendo afirmar que o processo de dominação do trabalho pelo capital precisou encontrar novas tecnologias de subordinação do trabalhador. Em suma, o processo produtivo necessitava ser mais racional e mais científico. Deve-se a Frederick Taylor (1856-1915) os primeiros esforços desta empreitada à medida que sistematizou ideias para uma Organização Científica do Trabalho (OCT), largamente utilizada e aperfeiçoada por Henri Ford. A OCT respondeu a necessidade de incrementar a produtividade de forma acelerada através de uma organização racional do trabalho: a partir da sua simplificação e divisão.

A questão geral que orienta as formulações de Taylor pode ser assim definida: Como organizar um sistema de produção que aumente os níveis de acumulação do capital sem aumentar a dependência do conhecimento e da subjetividade do trabalhador? Assim, Taylor irá se ocupar em estabelecer um método científico para aumentar a produtividade do trabalho, evitando a perda de tempo da produção, também conhecida como a Revolução da Produtividade. Propôs, então, que os movimentos do trabalhador deveriam ser controlados por uma gerência central e verticalizada. 
As ideias de Taylor fundaram o taylorismo, que transformou o processo de trabalho em "caixa-preta" para o trabalhador "através do controle das decisões que são tomadas no curso do trabalho" pelos "coordenadores e gerentes" (BRAVERMAN, 1977, p. 98). A passagem da manufatura fabril para a maquinaria é, então, caracterizada pela expropriação do controle sobre o "conteúdo, velocidade, intensidade, ritmo, etc. do trabalho [...] calculado com anterioridade com base no conhecimento das funções da máquina” (NETO, 1989, p. 28). No taylorismo, o processo de trabalho tornase científico com a introdução da maquinaria, porque permite um controle científico do processo de produção, possibilitando a libertação do capital da habilidade dos trabalhadores.

Braverman (1977) sistematiza em três os princípios do taylorismo: 1) dissociação do processo de trabalho das especialidades dos trabalhadores; 2) separação de concepção e execução; e 3) utilização do monopólio do conhecimento para controlar cada fase do processo de trabalho e seu modo de execução. Nesta perspectiva, cabe ao fordismo, caracterizado como um processo de trabalho organizado a partir de uma linha de montagem, o "desenvolvimento do taylorismo no sentido da busca do auxílio dos elementos objetivos do processo (trabalho morto), no caso da esteira, para objetivar o elemento subjetivo (trabalho vivo)" (NETO, 1989, p. 35), reinventando a divisão do trabalho como geradora de produtividade e destituindo o trabalhado de qualquer conteúdo subjetivo, uma vez que a ação do trabalhador vê-se reduzida à simples repetição de gestos no processo do trabalho. $\mathrm{O}$ fordismo investiu na especialização rígida, mas com base tecnológica diferenciada do taylorismo; todavia, ambos estão calcados em mecanismos de subordinação dos trabalhadores.

No entanto, passada a euforia dos resultados da OCT sobre o controle dos trabalhadores no processo de produção, percebeuse que este sistema, caracterizado pela rigidez, gerava obstáculos para a acumulação de capital "ao introduzir descontinuidades dentro do processo de produção, ao igual que entre a produção e circulação por conectar efetivamente a produção com o mercado" (ROJAS, 1987, p. 39). Além disso, a divisão do trabalho elevada ao extremo conduzia a empresa a um estágio de rendimentos decrescentes; e o trabalho concebido sem nenhum conteúdo de inteligência e intervenção operária logo se mostrou como uma ilusão tecnicista. A excessiva preocupação pela rapidez, os tempos 
e os movimentos se depararam com a fadiga e o esgotamento dos trabalhadores. Além disto,

A racionalização do processo de trabalho, com o aprofundamento da separação concepção/execução, da decomposição e simplificação das tarefas foi uma das "invenções" do capital que viabilizou aquele avanço, ao submeter os trabalhadores a modos de trabalhar concebidos fora da experiência prática cotidiana dos próprios trabalhadores e que implicaram na destruição do conhecimento adquirido naquela experiência, tornando-o obsoleto. (SILVA, 1992, p. 80).

Desta maneira, mais que a preocupação com as tarefas que o trabalhador deve desempenhar, as metodologias de análise que propõem a reestruturação do fordismo centram-se em decifrar e estabelecer a contribuição do talento humano para a consecução dos objetivos das empresas, isto é, de acumulação do capital. Com este objetivo surge o toyotismo - com um conceito de continuidade e ao mesmo tempo de descontinuidade com o fordismo e se apresentando por meio de protocolos organizacionais voltados para realizar uma nova captura da subjetividade operária pela lógica do capital, modificando o conceito de coerção dos trabalhadores empregado desde o capitalismo fabril pelo “consentimento operário". Nos anos 80, o Japão exportou técnicas organizacionais: CCQs, Just-in-time, TCQ (Total Quality Control), Kaisen (busca de melhoria contínua), 5Ss, TPM (Total Productive Maintenance). Este fenômeno foi conhecido como mundialização do toyotismo. Mas, diferentemente do fordismo, caracterizado por uma rigidez produtiva, o toyotismo irá adaptar-se de acordo com o contexto em que será aplicado, principalmente de acordo com a qualificação da mão de obra para sua implementação. Os protocolos organizacionais do toyotismo, que inscreveram uma nova via de racionalização do trabalho pela autonomação/autoativação, just-in-time/kanban e a polivalência operária, inverteram a lógica do acúmulo do capital não pela divisão do trabalho e pela rapidez da operação individual do trabalhador no processo de produção, mas pelo 'engajamento estimulado' em uma equipe de trabalho para otimização da produção, gerando operários com "responsabilidade pela qualidade dos produtos nos próprios postos de fabricação" (ALVES, 2000, p. 43).

Segundo Alves (2000, p. 31), o toyotismo tenta capturar a subjetividade operária, "não como um novo modelo de regulação, 
mas um neo-fordismo". O autor acredita que o toyotismo é uma inovação por conta da maneira como irá realizar a captura do aspecto subjetivo dos trabalhadores, por isso o considera a terceira revolução industrial, porque exige uma nova subjetividade operária. Assim, o toyotismo surgiu com o objetivo de "promover uma subjetividade operária para uma nova racionalização do trabalho" (ALVES, 2000, p. 32), para um efetivo controle da subjetividade dos trabalhadores como uma espécie de "terceira revolução industrial e tecnológica”, mas que não qualificou o trabalho, uma vez que o pluriespecialismo é o trabalho despojado de seu conteúdo concreto.

Desta maneira, o trabalho chega à sociedade atual de forma multifacetária. Segundo Singer (2000), estamos vivendo uma mal-estar no final do século XX com o aparecimento de índices estruturais de desemprego, aliados a conceitos como "flexibilização do trabalho", que indicam uma sensível precarização do trabalho principalmente por eliminar garantias e avanços trabalhistas, como estabilidade e vínculo formal, e "Exército Industrial de Reserva", que compreende o desemprego como variável estratégica de dominação do capital, aliado à fragilização da ação coletiva dos trabalhadores que acabam por aderir à reestruturação flexível. Para Neto (1996), "o exército de reserva torna-se, ao mesmo tempo, a base da fragilização dos sindicatos tradicionais e da introdução da ideologia da cooperação" (NETO, 1996, p. 94). Segundo o autor, a redução da resistência operária é um ingrediente salutar para o aumento dos níveis de acumulação capitalista.

\section{Considerações finais}

Alheia ao debate sobre o caráter paradigmático das crises e reestruturações capitalistas, a intenção deste estudo é problematizar os elementos que justificam que as crises têm origem no esgotamento da capacidade de acumulação do capital, exigindo sua reestruturação. No entanto, o elemento que caracterizará o "novo capitalismo" nunca é causa nem consequência da crise, mas uma oportunidade de revitalização do sistema, isto é, aumento dos níveis de acumulação do capital. Nas palavras de Rojas (1987, p. 27): "o que significa uma tragédia para a maioria dos trabalbadores e muitos capitalistas particulares e nações, é a bênção disfarçada para muitos e - sobretudo - para o capitalismo como tal". Neste sentido, o aspecto central desta reestruturação é a mudança da forma de 
coerção dos trabalhadores e de controle sobre o trabalho para o melhoramento dos níveis de acumulação. Por um lado, esta condição argumenta em favor da tese da centralidade do trabalho, inclusive na sociedade atual, da mesma maneira que os dados da divisão internacional do trabalho indicam que não estamos diante do fim da industrialização, mas apenas do seu deslocamento no espaço, como é o caso dos países de centro que se desindustrializaram e cujos empregos passaram basicamente a ser de serviços, ao tempo que os países periféricos e semiperiféricos tornaram-se verdadeiros polos industriais.

Neste ponto, Antunes (2005) afirma que a adoção do toyotismo como modelo de organização produtiva coloca em cheque algumas conquistas importantes dos trabalhadores, consolidadas no Welfare State, uma vez que o contexto destes "protocolos organizacionais" é o da expansão neoliberal. Segundo o autor, esta situação obrigou muitos governos a articular uma repressão aguda contra o movimento dos trabalhadores. Tal repressão, organizada pelo regime de acumulação flexível, significou a perda de muitas conquistas da classe trabalhadora à medida que reduziu o número de trabalhadores fabris, o aumento do emprego terceirizado, desqualificação e fragmentação da força de trabalho. Mesmo assim, Antunes argumenta que esta tendência não pode ser entendida como homogênea e unidirecional à medida que indicaria o "fim do trabalho", mas se trata de uma

[...] processualidade contraditória e multiforme, uma vez que outros modelos de organização produtiva, inclusive o modelo fordista, sobrevivem em setores econômicos e em diferentes contextos do capitalismo global. Isto permite concluir que nem o operariado desaparecerá tão rapidamente e, o que é fundamental, não é possível perspectivar, nem mesmo num universo distante, nenhuma possibilidade de eliminação da classe-que-vive-do-trabalho. (ANTUNES, 2005, p. 10).

Outro autor que merece destaque na crítica ao trabalho abstrato que mantém uma constante em todas as crises e reestruturações produtivas do sistema capitalista é Robert Kurz (1999). Segundo o autor, o Estado (tanto socialista como capitalista) teve o papel central na transformação dos produtores diretos em trabalhadores assalariados. Essa tese leva em conta que o trabalho assalariado é centralmente abstrato porque interrompe a relação entre o produto e o seu produtor. Para Kurz, 
o Estado criou as condições para a disciplinarização da massa de trabalhadores, para a transformação da classe trabalhadora em uma grande máquina de trabalho abstrato.

A realidade do mundo do trabalho contemporâneo evidencia que se multiplicam as situações de trabalho precário, intermitente, sub-remunerado e sem proteção social regular. Pesquisas recentes mostram que, na Europa,

[...] dos 18 milhões de novos postos criados nos anos 80, apenas $12 \%$ podem ser considerados bons empregos. E que no seu funcionamento normal, a economia de mercado não promove a homogeneidade. Pelo contrário, as desigualdades são necessárias, tanto quanto a concorrência que facilita a exclusão dos 'inadequados. (CATTANI, 1996, p. 56-59).

Neste sentido, merecem atenção aspectos centrais da reestruturação capitalista nos dias atuais, como a descentralização e a flexibilidade automatizada, bem como o impacto das novas Tecnologias da Informação (TIs) no controle do trabalho, problematizando-se a sua suficiência como "novos mecanismos de subordinação dos trabalhadores” (ROJAS, 1987, p. 22). Assim como deverão ser objetos de análise as recentes crises capitalistas e as novas formas de organização com o advento da sociedade em rede, o que vem alterando as configurações de espaço e tempo do capitalismo mundial. Além disto, novos temas como a pluriatividade e a ampliação do espaço das mulheres no mercado de trabalho somam-se às questões que deverão ser analisadas para compreensão da atual dinâmica do mundo do trabalho, problematizando se e como estes temas são incorporados pela atual reestruturação produtiva na obtenção da subjetividade operária para ampliação dos níveis de acumulação do sistema capitalista, levando em consideração que esses "níveis" precisam, necessariamente, significar o trabalho de maneira abstrata, portanto, não emancipadora.

\section{Referências}

ALVES, Giovani. O novo (e precário) mundo do trabalho. São Paulo: Boitempo, 2000.

ANTUNES, Ricardo. Adeus ao trabalho? Ensaios sobre a metamorfose e centralidade do mundo do trabalho. 10. ed. São Paulo: Cortez, 2005.

ARENDT, Hannah. A Condição Humana. Rio de Janeiro: Forense 
Universitária, 1983. 3. ed. São Paulo: Boitempo, 1999.

BRAVERMAN, Harry. Trabalho e Capital Monopolista. 3. ed. Rio de Janeiro: Zahar, 1977.

CASTELLS, Manuel. A Sociedade em Rede. 2. ed. São Paulo: Paz e Terra, 1999.

CATTANI, Antônio. Trabalho e Autonomia. Petrópolis, RJ: Vozes, 1996.

DECCA, Edgar de. A ciência da produção e a fábrica despolitizada. Revista Brasileira de História, n. 6, 1984.

O Nascimento das Fábricas. São Paulo: Brasiliense, 1996.

DUBAR, Claude. Os debates sobre o futuro do trabalho na França. Revista Latinoamericana de Estúdios del Trabajo, ALAST, 1998.

HOLZMANN, Lorena. Operários sem patrão: gestão cooperativa e dilemas da democracia. São Carlos: EdUFSCar, 2001.

HUMPHREY, John. Métodos Japoneses e Operários de Produção. Evidências a partir da América Latina. Cadernos de Sociologia do Trabalho, Porto Alegre, v. 4, n. 4, 1992.

KURZ, Robert. O Colapso da Modernização: da derrocada do socialismo de caserna à crise da economia mundial. Trad. Karen Elsabe Barbosa. 5. ed. São Paulo: Paz e Terra, 1999.

MARGLIN, Stephen. Origem e Funções do Parcelamento das Tarefas (para que servem os patrões?) In: GORZ, André. Crítica da Divisão do Trabalho. São Paulo: Martins Fontes, 1980.

MARX, Karl. Manuscritos Econômico-Filosóficos. Lisboa: 70, 1989.

MASI, Domenico de. O ócio criativo. Rio de Janeiro: Sextante, 2000.

NEFFA, Júlio César. Crisis y Emergencia de Nuevos Modelos Productivos. In: LA GARZA, Enrique. Los Retos Teóricos de los estudios del trabajo hacia el siglo XXI. Buenos Aires: Clacso, 1999.

Los paradigmas productivos taylorista e fordista y su crisis. Buenos Aires: Ed Lumen, 1998.

NETO, Benedito de M. Marx, Taylor e Ford. As forças produtivas em 
discussão. São Paulo: Brasiliense, 1989.

NETO, José Meneleu. Desemprego e luta de classes: as novas determinantes do conceito marxista de exercito industrial de reserva. In: TEIXEIRA, Francisco J. S.; OLIVEIRA, Manfredo Araújo de. Neoliberalismo e reestruturação produtiva. São Paulo: Cortez; Fortaleza: UECE, 1996.

POSCHMANN, Márcio. O trabalho sob fogo cruzado. São Paulo: Contexto, 1999.

ROJAS, Fernando; PALACIO, Germán. Tecnologia de la información: una nueva estrategia de subordinación de los trabajadores. Cuadernos de Economia, Bogotá, Universidad Nacional de Colombia, n. 11, 1987.

SILVA, Josué Pereira da. A crise da sociedade do trabalho em debate. Revista Lua Nova/35, São Paulo, 1992.

SILVA, Lorena Holzmann. Organização do Trabalho: controle e acumulação. Cadernos de Sociologia do Trabalho, Porto Alegre, v. 4, n. 4, 1992.

SINGER, Paul. Globalização e Desemprego: diagnóstico e alternativas. São Paulo: Contexto, 2000.

THOMPSON, E. P. Costumes em Comum. São Paulo: Companhia das Letras, 1998.

\title{
LABOUR RELATIONS AND PRODUCTIVE RESTRUCTURING INTHE WESTERN CAPITALISM:THE CRISIS AND THE (NEW) CONTROL DEVICES
}

\begin{abstract}
This article analyzes the crises and the consequent restructuring production that marked the history of capitalism occidental from the perspective of the new devices that have marked labor relations in each of these steps. For this, he develops a brief history of labor from the new control devices installed on employees in the course of restructuring. The background is present theoretical elements to justify that beyond discourse humanization of work, new factors came into play capture the subjectivity working to increase capital accumulation. These preossupostos lead to the conclusion that at present the challenge of overcoming the precariousness of labor persists and becomes a social imperative considering the importance of work as a key element of human socialization.
\end{abstract}

Keywords: Labor relations. Crisis. Economic restructuring. 